\title{
Artificial intelligence in molecular imaging: at the crossroads of revolutions in medical diagnosis
}

Progress in medical imaging evolves slowly but is occasionally punctuated by great leaps forward. Rarely do two such leaps coincide, thereby enabling synergistic improvements in detection, staging, and prognostication for patients. Yet, we are witnessing that in real-time, with rapid progress in both molecular imaging (MI) and artificial intelligence (AI).

This series of articles in Annals of Translational Medicine explores the intersection of MI and AI and hints at the future impact of these rapidly changing technologies. Manuscripts include both original research and review articles that cover topics such as the use of generative adversarial networks (GANs) in medical imaging, molecular neuroimaging, the use of AI for response assessment, and prostate-specific membrane antigen (PSMA)-based therapy in prostate cancer, among others.

As the number of clinically utilized radiotracers increases, the information available from inherently data-rich MI will expand, providing insight into physiology and pathology across systems that are working as independent networks yet in concert. Meanwhile, the sophistication of AI algorithms will increase as larger volumes of MI data are leveraged to guide patient management with unprecedented levels of precision.

Looking forward, progress in MI and AI will not occur independently, but will instead be inextricably linked. All aspects of MI will be impacted by AI and the field will accelerate as AI is brought to bear on new radiotracer development, the reconstruction of ultra-low-dose scans, and outcomes prediction from whole-body imaging metrics. Concurrently, the layered functional and molecular information available from MI will drive the development of AI algorithms whose predictive qualities will be dramatically improved over those possible with anatomic imaging alone. The articles in this series will serve as an introduction to these topics.

\section{Acknowledgments}

Funding: None.

\section{Footnote}

Provenance and Peer Review: This article was commissioned by the editorial office, Annals of Translational Medicine for the series "Artificial Intelligence in Molecular Imaging". The article did not undergo external peer review.

Conflicts of Interest: The author has completed the ICMJE uniform disclosure form (available at http://dx.doi.org/10.21037/ atm-2020-mi-09). The series "Artificial Intelligence in Molecular Imaging" was commissioned by the editorial office without any funding or sponsorship. SPR served as the unpaid Guest Editor of the series and serves as an unpaid editorial board member of Annals of Translational Medicine from Mar 2020 to Feb 2022. SPR reports personal fees and other from PlenaryAI, outside the submitted work; In addition, SPR has a patent A Machine Learning Framework for Classification of Cancer Lesions on PET pending, and a patent Methods and Related Aspects for Medical Image Generation pending.

Ethical Statement: The author is accountable for all aspects of the work in ensuring that questions related to the accuracy or integrity of any part of the work are appropriately investigated and resolved.

Open Access Statement: This is an Open Access article distributed in accordance with the Creative Commons AttributionNonCommercial-NoDerivs 4.0 International License (CC BY-NC-ND 4.0), which permits the non-commercial replication and distribution of the article with the strict proviso that no changes or edits are made and the original work is properly cited (including links to both the formal publication through the relevant DOI and the license). See: https://creativecommons.org/ licenses/by-nc-nd/4.0/. 


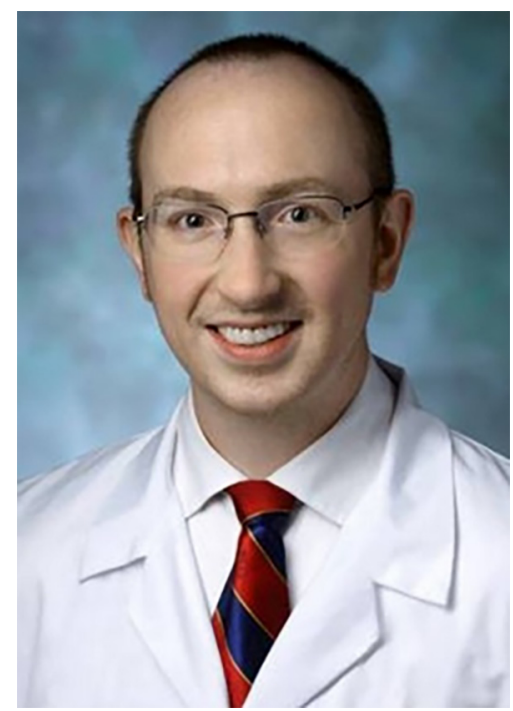

Steven P. Rowe

Steven P. Rowe, MD, PhD

The Russell H. Morgan Department of Radiology and Radiological Science, Johns Hopkins University School of Medicine, Baltimore, MD, USA. (Email: srowe8@jbmi.edu)

Submitted Dec 22, 2020. Accepted for publication Dec 31, 2020. doi: 10.21037/atm-2020-mi-09

View this article at: http://dx.doi.org/10.21037/atm-2020-mi-09

Cite this article as: Rowe SP. Artificial intelligence in molecular imaging: at the crossroads of revolutions in medical diagnosis. Ann Transl Med 2021;9(9):817. doi: 10.21037/atm2020-mi-09 